\title{
An Integrated Construction Management Approach for Addressing LEED Project Challenges
}

\author{
Andrea N. Ofori-Boadu ${ }^{1}$, Lee Addo ${ }^{2}$, Mariam Adebakin ${ }^{1}$ \\ ${ }^{1}$ (Department of Built Environment, College of Science and Technology, North Carolina Agricultural and \\ Technical State University, United States of America) \\ ${ }_{2}^{2}$ (Sterling Construction Services, United States of America)
}

\begin{abstract}
Notwithstanding the progress that has been made in the Leadership in Energy and Environmental Design (LEED) program, engineering and construction professionals express frustrations with meeting the stringent criteria required to earn LEED building certifications. Without effective management practices, LEED project challenges can minimize the capacity of construction organizations to achieve LEED project certifications in a cost-effective and timely manner. The main purpose of this study is to explore LEED project challenges and develop an integrated construction management approach for minimizing LEED challenges. A mixed method approach utilizing surveys and a case study was adopted for this research project. Responses obtained from surveys completed by construction professionals were clustered into common themes and analyzed. Furthermore, interviews and LEED project document reviews were employed to examine the management practices implemented by joint venture partners on an ongoing LEED project. Results revealed four clusters of LEED challenges: Constructing LEED buildings (43\%); Tracking LEED credits (26\%); Understanding LEED requirements (22\%); and Accessing LEED resources (9\%).

Drawing from these results and the case study, an integrated construction management approach for enhancing LEED project success was developed. The key components of this approach are project-specific, organization, and industry-wide practices. This approach should reduce LEED project challenges, and improve LEED project success.
\end{abstract}

Keywords: Project management, construction organizations, LEED, sustainable, green

\section{Introduction}

The development of the built environment has dramatically altered the natural environment, raising serious concerns about the design, engineering, construction and disposal of buildings. In the last couple of decades, there has been a global push for the increased implementation of sustainable design and construction practices in an effort to minimize the negative impacts that have resulted from built environments. Notably, the construction industry has been blamed for numerous environmental problems, including but not limited to soil erosion, desertification, pollution, ozone depletion, acidification, loss of biodiversity, loss of natural habitats, fisheries depletion, eutrophication, and poor human health (Kibert, 2008). Environmental advocates are critical of the negligent, unhealthy and unsafe materials and methods used during building development. Prevalent negative environmental issues correlate with unsustainable practices such as poor building design, excessive resource consumption, high energy consumption, high levels of construction material wastes, and use of toxic products (Ding, 2008; Myers, 2005). In response to the call for sustainable building design and construction, several building assessment and certification programs have been developed. These programs include the Building Research Establishment Environmental Assessment Methodology (BREEAM), ENERGY STAR Program, and the Leadership in Energy and Environmental Design (LEED) Program.

In 1993, the U.S. Green Building Council (USGBC) was established with a mission to promote sustainability-focused principles and practices for built environments and the construction industry. Through an open and balanced coalition spanning the entire building industry, the LEED green building rating system was developed and unveiled in 2000. This pilot LEED version has evolved over the years into the most current rating system - the LEED v4. Currently, most ongoing LEED projects either comply with either LEED 2009 or LEED v4. LEED has become an international standard for environmentally sound buildings, and it is the most widely used third-party verification for a variety of green buildings around the world, with approximately 1.85 million square feet of buildings being certified daily (USGBC, 2016). The four most recent LEED v.4 Rating System are for Building Design and Construction; Interior Design and Construction; Building Operations and Maintenance; and Neighborhood Development. Building projects that pursue LEED certification must earn points in several key areas that address sustainable issues. These include location and transportation, sustainable sites, energy and atmosphere, material and resources, indoor environmental quality, innovation, and regional priority. Based on the points earned, a certified building can receive one of four rating levels: Platinum, Gold, Silver, or Certified, with Platinum being the highest building sustainability rating. Compared to conventional 
buildings, LEED-certified buildings are more resource efficient, reduce greenhouse gas emissions, use less water and energy, and save money (USGBC, 2016). Several researchers have documented the efficient performance of LEED buildings (Heerwagen, 2000; Abbaszadeh, Zagreus, Lehreh, and Huizenga, 2006; and Miller and Spivey and Florence, 2008). It is commonly believed that certified LEED buildings use less energy (embodied and in-use) resulting in reduced fossil fuel emissions over the life of the project - from conception, through occupation, use and final demolition/ dismantling. Due to its perceived benefits, the demand for LEED buildings has escalated in recent times. USGBC (2016) listed 91,439 LEED-certified buildings, 12,000+ affiliated organizations, and 200,000+ professionals and volunteers.

Green building is growing across the globe as compared to $13 \%$ in $2009,28 \%$ of architects, engineers and contractors reported that $60 \%$ of their work in 2012 was on green projects. The green share of project activity for the firms sampled in the 2013 McGraw Hill Construction study was 38\%. Furthermore, the McGraw Hill study confirmed that the strongest driver of green projects was client demand (35\%), closely followed by market demand (33\%), lower operating costs (30\%), branding / public relations (30\%), right thing to do (26\%) and market transformation (18\%) (McGraw Hill, 2013). In the United States, many local, national and federal governments are adopting green building standards. The increase in client demand for green buildings merits that engineering and construction professionals enhance their green building strengths in order to be competitive and increase their market share. The ascent of the green building market has challenged several design, engineering and construction organizations to implement sustainability practices, such as those approved by the LEED program. Beyond the traditional project objectives - quality, time and cost, the management of LEED projects introduces a new objective - the environment. Despite the obvious environmental benefits, professionals are concerned about the challenges associated with trying to achieve one additional project objective. A significant challenge to managing LEED projects is the effective integration of different parties who are engaged in various phases of the design, development, utilization and disposal phases. Challenges associated with the early phases of the green building movement included lack of knowledge, lack of familiarity, complexity of LEED documentation process, and high green material costs (Goodson, 2004; France, 2007). In recent times, few studies such as Ofori-Boadu, Owusu-Manu, Edwards, and Holt (2012) and Corbett (2010) have addressed LEED challenges, considering that LEED has made some significant changes to its rating systems, its professional exams, and the tools available for its users. For example, the LEED online was launched recently to provide LEED users with a top-notch user experience. Beyond the LEED program, other significant changes in the green building world have been increased support from governments, increased client demand, improved availability of LEED professionals, as well as improved access to cheaper and more sustainable LEED products.

Despite advancements in the LEED program, construction professionals complain about its stringent requirements and the risks and the challenges that it presents to project success. Specifically, construction professionals express frustrations with meeting the criteria required to earn LEED building certification. Without understanding these challenges and providing solutions to minimize their impacts, LEED projects stand the risk of not being implemented in a cost-effective and timely manner. The main purpose of this research study is to explore LEED project challenges and develop an integrated construction management approach for minimizing LEED project challenges in order to enhance LEED project success.

\section{Methodology}

This IRB-approved mixed-methods research project employed a case study and a structured survey questionnaire which included questions on LEED project challenges and management strategies. The questionnaire was emailed to 50 construction professionals in North Carolina. They were selected due to their affiliation with an academic institution located in the Southeastern region of the United States. Six weeks after the initial emails, reminder emails were sent out. The data collection phase was closed at the end of the twelfth week. The contribution to the existing body of knowledge on sustainable construction principles and practices were drawn from empirical and rational processes that were used to assess data obtained from various construction professionals in different settings and situations. In analyzing the responses, descriptive statistical methods were used to obtain frequencies and means for various variables of interest. The underlying connection among research respondents was that they were engaged in LEED projects, and any recurring challenges and solutions that were noted in their responses regarding their various LEED experiences could be valuable to construction management professionals, and the construction industry as a whole.

Using multiple sources of evidence, a real-time case study was employed to examine prevalent LEED challenges and effective solutions implemented on an ongoing LEED project in the Southeastern region of the United States. The contractor for the LEED case study was selected because of the LEED project location, the contractor's listing on the top 100 green contractors list published by the Engineering News and Record (ENR), and the willingness of the contractor to participate in a LEED research study. In order to protect the contractor's identity, the pseudonym for the contractor is 'JOINTV' as a joint venture partnership exists between the lead 
contractor $(90 \%)$ and its minority partner $(10 \%)$. "REAL" was adopted as the pseudonym for the LEED project as it was a real-time LEED project. Methods of data collection utilized for the case study included the review of construction contract documents, review of meeting minutes and other project reports, interview of key personnel, and a review of related websites. These data collection methods are acceptable as Leedy and Ormrod (2001) recommended observations, interviews, narratives, and other data sources such as audio-visual material for case study research. While demographic information obtained from all of the survey participants was quantitatively analyzed, the responses to open-ended questions were analyzed after classification into emerging themes. Due to the focus on the procedures and protocols of the contractors, this qualitative deductive procedure worked best for this level of research inquiry (Holt and Edwards, 2012). Since the authors' experience formed the basis of subjective analysis and discussion, an axiological disposition was adopted along with an action research philosophy.

\section{Results And Discussion}

\subsection{Description of Construction Professionals and their Organizations}

The response rate for this research study was $60 \%$. However six of the completed surveys were removed from the data set due to lack of LEED knowledge, LEED experience and/or excessive missing data. On average, participants had 14 years of working experience and had worked on four LEED projects. Out of the 24 participants, 83\% had a bachelor's degree and 17\% had a master's degree; and LEED Accredited Professionals (LEED-AP) made up 50\% of the participants. Their position titles included Project Engineers, Estimators, Project Managers, Vice-Presidents and Presidents. Over 75\% of the participants worked for General Contractors, who had over 51 employees with annual revenues in excess of $\$ 500$ million. Further, these organizations had been operating for at least 30 years in the United States, and had completed more than 21 LEED projects. Approximately $20 \%$ of the respondents worked for subcontractors, and the remaining were either General Contractors or Construction Management organizations or both.

\subsection{Description of the REAL Project}

The REAL project is a new 2-story, 39-classroom elementary school building with over 80,000 sf of building area. The spaces in the building include a kitchen, multipurpose dining / gymnasium, media center and administrative wing. The LEED features for the REAL project included public transportation access, lowemitting and fuel efficient vehicles, water efficient landscaping, water use reduction, optimizing energy performance, construction waste management, recycled/regional materials, Forest Stewardship Certifications (FSC) wood, low-emitting materials and LEED AP. These were documented on the LEED checklist and in the Project Manual. The Guaranteed Maximum Price for this REAL project is $\$ 15,000,000.00$, not including LEED certification fees. Further, no LEED premiums were applied to the construction cost estimate. The lead project team members from both partners to the joint venture are LEED-Accredited Professionals (LEED-APs), and have a wide range of LEED experiences that brought significant value to this research study. In particular, the Vice-President of the lead partner firm had been actively involved in USGBC activities, as well as engaged in sustainability outreaches to K-12 students. With sustainability being one of the core values of the lead partner to the REAL project, its corporate office is a LEED-GOLD building, which recycled and diverted $95 \%$ of its construction waste from landfills, materials with recycled content and used energy alternatives to reduce gas usage. This building has an irrigation system which collects rainwater and uses gray water, thereby utilizing $40 \%$ less water than required by the minimum standards of the U.S. Environmental Protection Agency.

\subsection{Description of LEED Project Challenges}

Research participants provided responses to survey items that requested information on technical and managerial challenges faced on LEED projects. The technical challenges were directly related to the materials, methods, equipment and other resources utilized in the construction of LEED buildings, while the management challenges referred to the processes for planning, supervising and controlling the project activities.

\subsection{Sources of LEED Technical and Managerial Challenges}

The sources of the LEED challenges were of interest in this study, because knowing the source of a problem is a critical step to solving the problem. The source refers to the party or the member of the project team that caused or initiated the identified problem. The participants' responses were assessed and drawing from the more frequently recurring challenges, the responses were categorized into seven thematic groups. While some participants clearly stated the party responsible for the problem, others assigned the problem to the entire project team. As shown in Table 1, subcontractors were the primary source of both technical and managerial challenges. Thirty-eight percent of the participants' responses indicated that subcontractors were the source of technical challenges on their LEED project. 
Table 1. Sources of LEED Challenges.

\begin{tabular}{|l|c|c|}
\hline Source & Technical Challenges (\%) & Managerial Challenges (\%) \\
\hline Subcontractors & 38 & 53 \\
\hline General Contractors & 35 & 30 \\
\hline Project Team & 3 & 8 \\
\hline Architect/Engineer & 8 & 3 \\
\hline USGBC & 13 & 6 \\
\hline Client & 3 & 0 \\
\hline
\end{tabular}

Respondents noted that subcontractors struggled to comply with the technical specifications for the LEED products and they often lacked technical skills. Despite the pre-construction meetings held with subcontractors to introduce them to the relevant LEED requirements, the Project Engineer raised concerns about subcontractors failing to keep ducts covered and forgetting to supply appropriate product data on paints with low volatile organic compounds (VOC). The REAL project team addressed this weakness by having regular supervisions and including LEED compliance in their project close-out requirements. Furthermore, the submittal process was thorough and required extensive checks and approvals before construction work could begin. Thirteen percent $(13 \%)$ of the participants emphasized that LEED technical requirements provided by USGBC were unclear and confusing. In addition, it was difficult to obtain clarification and obtain answers to specific questions regarding LEED implementation. Furthermore, two respondents complained that downloading LEED documents from the USGBC website was very slow. Eight percent (8\%) of the respondents noted that the LEED project team relied heavily on the architects and engineers who were sometimes not knowledgeable enough about LEED requirements. Other minor concerns were regarding the knowledge levels of the project team and the clients' concerns regarding LEED project costs.

Further analysis focusing on the managerial LEED challenges showed that $53 \%$ of the respondents associated LEED managerial challenges with subcontractors, while $30 \%$ assigned challenges to General Contractors. The prevailing issues for subcontractors and General Contractors were with LEED calculations, tracking of LEED data and LEED building costs. The REAL project had two experienced LEED-APs who were experts in tracking and documenting LEED credits, and so the project did not face excessive LEED data tracking problems. However, the REAL Project Engineer noted that keeping logs, regional material calculations, pre and post-consumer documentation were challenging. Subcontractors had to be pursued regularly with emails and telephone calls to remind them to submit required LEED documentation. It must be noted here that the REAL project had stringent protocols and penalties in place for non-compliance.

\subsection{Clusters of LEED Project Challenges}

Four cluster themes of LEED project challenges emerged from the assessment of participant responses, with the most frequent challenges being associated with the physical construction processes associated with LEED buildings. This was closely followed by challenges associated with the tracking of LEED credits (Figure 1).

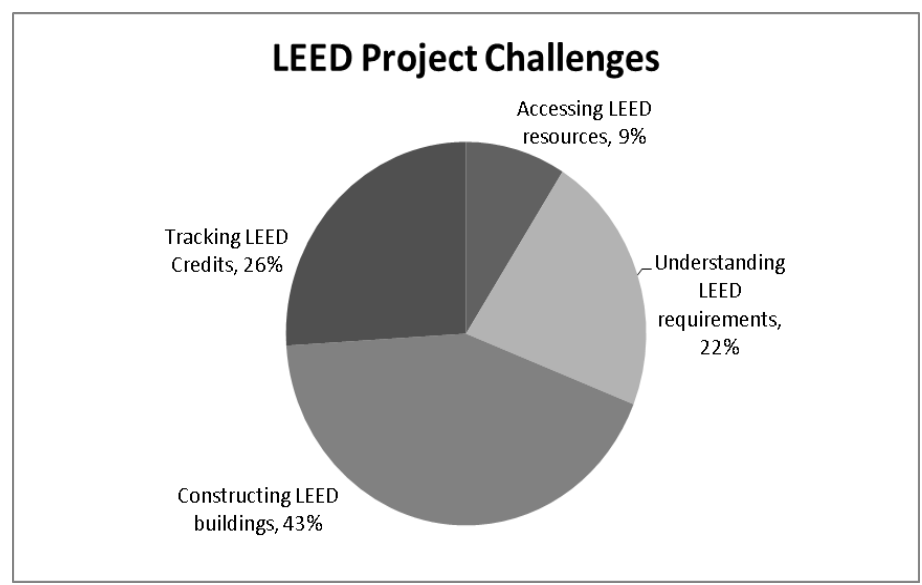

Fig. 1. Types of LEED Project Challenges

\subsubsection{Constructing LEED Buildings}

Forty-three percent $(43 \%)$ of the responses indicated significant challenges during the physical construction of LEED buildings. They claimed that sustainable materials and processes are expensive and presented higher upfront costs to the General Contractor. Also, subcontractors sometimes made serious mistakes and omitted important LEED materials and processes. Drawing primarily from their experience with 
conventional buildings, subcontractors would supply materials that did not comply with LEED requirements. Considering these challenges, General Contractors had to dedicate additional time, effort and resources to the supervision of subcontractors on the LEED projects. They emphasized that although subcontractors lacked adequate knowledge and familiarity with LEED, they were mostly unwilling to invest additional resources to ensure LEED project success. Tight budgets made it difficult for project managers to commit fully to achieving LEED requirements. On the other hand, subcontractors also complained of the additional work and resources that they had to invest in order to research and locate materials and products that would be approved by the LEED project team. A mechanical subcontractor alluded that the products specified by the architects on LEED projects, sometimes did not even exist. Also, it took a much longer time to review and approve LEED submittals and thus increasing the chances for project delay.

\subsubsection{Tracking LEED Credits}

Twenty-six percent $(26 \%)$ of the responses indicated that tracking LEED credits was a major challenge. A major problem stems from the fact that subcontractors did not provide accurate and consistent data and so General Contractors were compelled to research for the data necessary to support their application for LEED credits. The Vice-President of the REAL project stated that sometimes subcontractors turned in submittals that had missing information, and so the project team had to go back and request missing data to ensure LEED compliance. General Contractors found the LEED paperwork process to be burdensome and time-consuming, sometimes affecting project progress schedules. The tracking of LEED credits are mostly ignored till the last minute, posing significant risks to the project success. It is imperative that the one or two members of the project team are assigned with the responsibility of monitoring, testing, documentation and tracking of LEED tasks. One participant stated that a major challenge with LEED projects was the rejection of the initial submission for LEED credits due to poor tracking efforts among the project team members. Ineffective communication channels between the architect and General contractor retarded progress, since they were primarily responsible for tracking LEED credits and submitting data for LEED credits. This necessitated re-submission of LEED application packages at additional costs to the contractor.

\subsubsection{Understanding LEED Requirements}

Twenty-two percent $(22 \%)$ of the responses indicated that understanding LEED requirements was a major challenge. Overwhelmingly, research participants concur that LEED project requirements are much more complex compared to conventional project requirements. Without prerequisite training in LEED, most professionals are unable to fully understand LEED requirements. Many general contractors struggled with understanding the LEED ratings and credits categories for their projects. Subcontractors in particular, are noted to usually have limited knowledge and understanding of LEED requirements. Nevertheless, they were not willing to invest into educating and training themselves to increase their performance on LEED projects. As stated earlier, the lead project team members for the REAL project were LEED-APs. The General Contractors on the REAL project commits funds and resources to educate and train its employees. Improved LEED knowledge and understanding should enhance LEED project success.

\subsubsection{Accessing LEED Resources}

Nine percent $(9 \%)$ of the responses indicated that accessing LEED resources was a major challenge. A few research participants who worked for general contractors complained about difficulty in accessing to LEED resources through the USGBC website. It is unclear whether the access issues were related to defective organizational information technology systems or to the USGBC website.

\subsection{An Integrated Approach for Minimizing LEED Project Challenges}

Drawing from the case study and survey responses, an integrated and insightful approach for minimizing LEED project challenges is proposed. This approach involves all stakeholders at various phases of LEED project development. In particular, engineering managers have to minimize LEED project challenges by making critical decisions and implementing strategies within the context of specific LEED projects, their construction organization and the broader construction industry. Project-specific, organization and industrywide practices that could enhance LEED project success are shown on Figure 2.

\subsubsection{Project-Specific Practices.}

These are short-term practices that are implemented during the development of specific LEED projects. The unique difference between conventional projects and LEED projects merits the implementation of projectspecific practices that should minimize LEED challenges and enhance project success. The recommended project practices listed in Figure 2 were obtained from lessons from the REAL project as well as responses from research participants. Due to the limitations of subcontractors and their related risks on LEED projects, 
emphasis is placed on the provision of education and training opportunities that are tailored to benefit subcontractors as they directly impact LEED project success. The inclusion of LEED-specific clauses in subcontracts and agreements, as well as the implementation of standard LEED procedures, protocols, and checklists are strongly recommended. Pre-construction meetings, regular monthly meetings and extensive site supervision are also very necessary for the successfully attainment of LEED project objectives. Furthermore, the presence of LEED-APs and LEED consultants on project teams add significant value to LEED projects. By implementing project-specific strategies, engineering managers ensure that their project team members are provided with the knowledge and resources necessary to easily identify specific LEED project challenges and implement effective interventions in a timely and cost-effective manner. These practices should improve LEED project success due to the potential to minimize undesirable negative impacts such as delays, reduced profits, losses, strife and litigation.

\subsubsection{Organizational Practices}

The organizational practices shown in Figure 2 are derived from survey responses, the REAL project case study, and from literature reviews (Ofori-Boadu, Owusu-Manu, Edwards and Holt, 2012; Corbett, 2010). The intuitive framework harmonized organizational practices with sustainable development for green building contractors. It is important that the leaders of organization are committed to sustainability and promote core values that reflect organizational commitment to sustainability. One of the strengths of the REAL project is that its Vice-President is very engaged in USGBC professional development and outreach activities. The knowledge, understanding and experiences gained from networking and engaging in broader external sustainability events can be used to improve organizational practices. Further, this general contractor provides resources, incentives, and an organizational culture that promotes sustainability. For example, they reimbursed employees who took LEED tests and participated in sustainability-related professional development events. A laudable and strong demonstration of this general contractor's commitment to sustainability is its headquarters - a LEED-GOLD certified building which recycled $95 \%$ of its construction waste. Both JOINTV organizations promote recycling and paperless practices at the organizational level.

\begin{tabular}{|c|c|c|c|c|c|}
\hline 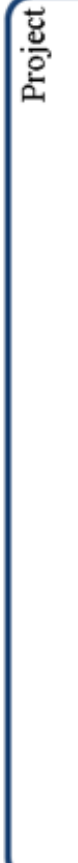 & $\begin{array}{l}\text { Employ a LEED -AP on } \\
\text { project team } \\
\text { Contract a LEED } \\
\text { consultant } \\
\text { Detail LEED } \\
\text { requirements in } \\
\text { subcontract agreements } \\
\text { Hold pre-construction } \\
\text { meetings for LEED scope } \\
\text { of work } \\
\text { Increase site supervision } \\
\text { and monitoring } \\
\text { Provide LEED updates at } \\
\text { weekly meetings } \\
\text { Adopt LEED checklists, } \\
\text { forms and protocols } \\
\text { Educate and train all } \\
\text { project staff on LEED } \\
\text { Provide LEED related } \\
\text { professional development } \\
\text { oportunities to } \\
\text { subcontractors }\end{array}$ & 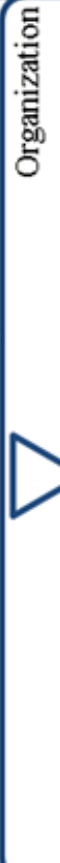 & $\begin{array}{l}\text { Increase leadership } \\
\text { committment to } \\
\text { sustainability } \\
\text { Adopt sustainability as a } \\
\text { core organizational value } \\
\text { Provision of resources to } \\
\text { build the capacity of } \\
\text { organization for LEED } \\
\text { project success } \\
\text { Develop a LEED- } \\
\text { intelligent workforce } \\
\text { Implement systems of } \\
\text { incentives and rewards } \\
\text { for LEED success } \\
\text { Implement Subcontractor } \\
\text { Development Program }\end{array}$ & 宓 & $\begin{array}{l}\text { Participate in USGBC } \\
\text { events } \\
\text { Participate in local, state } \\
\text { and federal sustainable } \\
\text { construction and/or } \\
\text { develoment taskforces } \\
\text { Support research in } \\
\text { sustainable development } \\
\text { Diseminate lessons } \\
\text { learned and best practices } \\
\text { for LEED projects } \\
\text { Advocate for } \\
\text { Subcontractor } \\
\text { Development Programs } \\
\text { Broaden participation } \\
\text { through K-12 outreach } \\
\text { and other public } \\
\text { programs } \\
\text { Promote local, state and } \\
\text { federal policies and } \\
\text { programs which enhance } \\
\text { sustainability }\end{array}$ \\
\hline
\end{tabular}

Figure 2. Framework for Minimizing LEED Project Challenges.

Overwhelmingly, the results from this study demonstrated the critical need for subcontractors to be more enlightened about LEED processes and gain an improved understanding of the LEED program as a whole. As previously noted, subcontractors are unwilling to invest in human resource development that will enhance LEED project success. The limited knowledge and experience of subcontractors intuitively presents significant risks to the general contractor. While some training has been done by some general contractors at the project level, an industry-wide push for developing subcontractors may be necessary. Due to their heavy dependence on subcontractors for project success, General Contractors have to seriously consider implementing Subcontractor Development Programs (SDPs) in an effort to improve the performance of subcontractors on LEED projects. 
These SDPs are not common in the construction industry, but are becoming prevalent in the manufacturing industry. In developing their subcontractors, General Contractors should model existing supplier development programs used in the manufacturing industry. Easton (2000) defined supplier development as the transfer of resources (training, knowledge, information, equipment, materials, and capital) for the purpose of improving the performance and capability of suppliers. Krause (1995) listed supplier development activities to include: competition, informal supplier evaluation, feedback of supplier evaluation results, higher performance expectations, promise of current benefits, promise of future benefits, formal supplier evaluation, site visits, supplier certification, supplier recognition, exchange of personnel, training and education and direct capital investment. These subcontractor development programs could increase subcontractor performance and enhance LEED project success.

\subsubsection{Industry Practices}

These are long-term practices that need to be promoted and implemented by a significant proportion of engineering professionals and organizations in order to have an impact on the values, policies, programs and the overall direction of the entire construction industry. Drawing from research participants and literature reviews, Exhibit 3 shows industry wide practices that may be implemented to minimize LEED project challenges. Considering that there are significant risks associated with subcontractors on LEED projects, an industry wide promotion of Subcontractor Development Programs (SDPs) is recommended to improve subcontractor performance across the industry. Further research is needed to determine the structure of SDPs and the strategies needed to optimize its value to general contractors, clients and other stakeholders. In order to broaden participation and increase public awareness of sustainability practices, the construction industry should continue its outreach to underrepresented populations in sustainable development such as K-12 students. Beyond influencing personal sustainability practices, outreaches have the potential to stir up the interests and persistence of students towards professions that contribute to the advancement of sustainability in the United States. An informed future workforce is critical for a more sustainable world. Lastly, the continued promotion of local, state and federal programs which support sustainable development is strongly encouraged (Ofori-Boadu, Shofoluwe, and Yeboah, 2013). An integrated approach towards the advancement of the principles and practices of sustainable development should reduce environmental degradation, which is one of the main goals of the entire LEED program.

Since LEED projects and construction organizations do not operate independently, but are significantly affected by the broader socio-technical industry environment, engineering managers should actively engage in industry-level programs and projects that positively influence and provide direction to the broader construction industry. Considering that decisions made by the broader industry trickles down and affects individual LEED projects, it is critical that engineering managers contribute to the advancement of sustainable design and construction policies and programs. They are at the fore front of specific LEED projects and are best equipped to share lessons and practices to promote LEED success. In the long term, strong advocacy and commitment from engineering managers to the broader mission and values of the construction industry could lead to the development of industry-level policies and programs which have the potential to minimize challenges and enhance LEED project success.

\section{Conclusion}

Despite advancements in LEED implementation, engineering and construction professionals experience significant challenges on LEED projects. These challenges are mostly associated with subcontractors, due to their limited knowledge and familiarity with the LEED program. To compound this weakness, subcontractors are often unwilling to invest resources to enhance their performance on LEED projects. The integrated approach for minimizing LEED project challenges involves all stakeholders and incorporates practices at the project, organization and industry levels. Notably, this approach is tailored to enhance performance at all three levels. In particular, General Contractors should seriously consider dedicating resources to Subcontractor Development Programs which are designed to build the capacity of subcontractors for LEED project success. Similar Supplier Development Programs are implemented in the manufacturing industry, and can be modified to meet the unique needs of the construction industry. This integrated approach should reduce LEED project challenges, and improve the capacity of LEED project teams to achieve LEED building certification in a cost-effective and timely manner. Future studies should assess the cost effectiveness of these practices, as well as explore other strategies that can be used to enhance the performance of subcontractors on LEED projects. Construction industry professionals and other stakeholders should promote the implementation of project-specific, organizational and industry wide practices that minimize challenges and enhance LEED project success. 


\section{Acknowledgements}

The authors want to acknowledge J.E. DUNN Construction Company and Sterling Construction Services for their assistance during this research project.

\section{References}

[1] Kibert, C. J. (2008). Sustainable construction- green building design and delivery (2nd ed.). Hoboken, New Jersey: John Wiley \& Sons, Inc.

[2] Ding, G.K.C. (2008). Sustainable construction - the role of environmental assessment tools. Journal of Environmental Management, 86(3), $451-464$

[3] Myers, D. (2005). A review of construction companies attitudes to sustainability. Construction Management and Economics, $23(8), 781-785$.

[4] U.S. Green Building Council (2016). LEED. Retrieved from U.S. Green Building Council: http://www.usgbc.org/leed

[5] Heerwagen, J. (2000). Green buildings, organizational success and occupation productivity. Building Research and Information, 28(5), 353-367.

[6] [Abbaszadeh, S., Zagreus, L., Lehreh, D. \& Huizenga, C. (2006). Occupant satisfaction with indoor environmental quality in green buildings. Retrieved from Center of Built Environment: http://www.cbe.berkeley.edu/research/pdf_files/Abbaszadeh_HB2006.pdf.

[7] Miller, N., Spivey, J., \& Florence, A. (2008). Does green pay off?. Retrieved from U.S. Green Building Council: http://www.usgbc.org/ShowFile.aspx?DocumentID=5537.

[8] Goodson, G. (2004). Notes from the log of a LEED navigator. Consulting Specifying Engineer, 1(February), 47-51.

[9] France, C. (2007). How to successfully implement LEED: documentation challenges and solutions. Journal of Green Building, 2(4), $2-13$.

[10] McGraw Hill Construction (2013). Smart Market Report: World green building trends. Retrieved from McGraw Hill:http://www.worldgbc.org/files/8613/6295/6420/World_Green_Building_Trends_SmartMarket_Report_2013.pdf

[11] Ofori-Boadu, A. N., Owusu-Manu, D-G, Edwards, D., \& Holt, G. (2012). Exploration of management practices for LEED project: Lessons from successful green building contractors. Structural Survey, 30(2), 145 - 162.

[12] Corbett, T. J. (2010). LEED challenges and risks for DoD projects. Retrieved from SMART RISK: http://c.ymcdn.com/sites/www.aiahonolulu.org/resource/resmgr/imported/Session\%2015_LEED\%20Challenges\%20and\%20Risks \%20for\%20DOD\%20Projects.pdf

[13] Leedy, P.D. \& Ormrod, J.E. (2001). Practical research - Planning and Design. Upper Saddle River, NJ: Prentice Hall.

[14] Holt, G. D. \& Edwards, D. J. (2012). Innovation or business survival? A preliminary, qualitative study of construction plant supply chains. Construction Innovation: Information, Process, Management, 12(1), 99 - 122.

[15] Easton, P. L. (2000). Antecedent conditions to supplier development success. Doctoral Dissertation, Arizona State University.

[16] Krause, D. R. (1995). Interorganizational cooperation in supplier development: Influencing factor. Doctoral dissertation, Arizona State University.

[17] Ofori-Boadu, A.N., Shofoluwe, M., \& Yeboah, F. E. (2013). An assessment of the predictors of U.S. commercial electricity consumption. International Journal of Engineering Research and Innovation, 5 (1), 76 - 89. 